\title{
JUAN MANUEL SANTANA PÉREZ y GERMÁN SANTANA PÉREZ, La pesca en el banco sahariano. Siglos XVII y XVIII, Los libros de la catarata, Madrid, 2014.
}

Hasta la extensión de la historiografía española hacia todos los rincones del Imperio, la historia de España terminaba en Cádiz, dónde empezaba otra historia -otra asignatura-, la historia de América. De lo que había más allá del Pacífico, o más al sur hasta el polo, no se ocupaba apenas nadie. Paradójicamente, la irrupción de la historia regional a partir de los setenta iba a producir una ampliación de las miradas históricas, que en lo concerniente a Canarias se dirigirían hacia África, hacia las culturas africanas con las que las islas han estado relacionadas milenariamente.

Los hermanos Santana, profesores en la Universidad de Las Palmas, Ilevan años investigando sobre la historia de los pueblos africanos del entorno al que pertenecen sus queridas islas, pues se dieron cuenta de que sin conocer a los vecinos que no llegaron del norte no se podía entender uno de los fenómenos que ha dado vida a la población de las islas durante la edad Moderna, la explotación pesquera, y que ha impulsado las relaciones entre las islas y los pueblos del noroeste africano, además de propiciar el desarrollo de las salinas en las islas y toda una forma de vida en torno al trabajo y la alimentación.

Todo ello está expuesto en este libro con claridad. La larga introducción es especialmente interesante, pues los autores describen el andamiaje del que se han valido para construir el relato: primero, la elección del XVII como punto de partida, "la última cabalgada; luego, los impulsos ilustrados tras el cambio de coyuntura, con el estancamiento de Gran Canaria y el incremento de los recursos dedicados a la pesca, al principio actividad de pobres, estigmatizada -más aún en las culturas ribereñas del continente que en las islas-; en adelante, hasta el final del Antiguo Régimen -que los autores Ilevan hasta 1837 con muy bien criterio-, impulsada por el gobierno, consciente del interés que comenzó a despertar el banco sahariano en las potencias europeas. "La riqueza del Banco Sahariano, uno de los más ricos del mundo, parecía casi ilimitada".

La explotación pesquera en auge durante el XVIII tuvo en la península a los catalanes como protagonistas, no sólo en el Mediterráneo sino incluso en Galicia, como demostraron Roberto Fernández y Carlos Martínez Shaw hace años, pero en las costas ribereñas, el concurso no fue solo de súbditos de la Corona española -en realidad, como señalan los autores, "fue un fenómeno casi exclu- 
sivamente canario"-, por lo que se hizo necesario regular la actividad mediante tratados, el más importante el suscrito por el primer embajador de España en Marruecos, Jorge Juan, muy consciente de que el sultán se veía presionado por franceses y que, obviamente, los ingleses estaban detrás. Y es que los autores son conscientes de tratar "aspectos de la internacionalización de Canarias en la historia, pero también se trata de una aportación a la historia de África y a la historia de la expansión atlántica".

Un excelente estado de la cuestión a partir del I Coloquio Internacional de historia marítima celebrado en París en 1956, con las aportaciones más interesantes en este espacio, hoy conocido en extensión y profundidad en lo relativo al mundo hispánico de ultramar gracias a las aportaciones de Carlos Martínez Shaw y Marina Alfonso Mola, da paso luego a un exhaustivo capítulo de fuentes, en el que se describen las nacionales, internacionales y locales, así como las procedentes de la prensa coetánea.

Los ocho capítulos del libro contienen el análisis histórico, centrados los primeros en el trabajo, la empresa, los precios y los salarios; el ámbito espacial, desde el cabo Aguer hasta el Banco de Arguín, con sus peculiaridades en las artes de pesca -y en otros fenómenos como el tráfico de esclavos-; el consumo, las diferencias de clase y los hábitos alimenticios, el "fresco" aportado por los pescadores ribereños, el "salado", el que se conservaba gracias a la sal producida por las salinas. A la extracción de este producto está dedicado el capítulo quinto, que en efecto es tan rico "que podría constituir una investigación monográfica aparte".

El capítulo seis está dedicado a los proyectos ilustrados, "los intentos de fomentar, ordenar y mejorar el sector, que marca la posterior evolución de la pesca canaria". Nos detendremos en él pues los autores explotan perfectamente las contradicciones de aquel régimen, "en manos de la aristocracia, y no de la burguesía como se había supuesto", que pretendió modernizar el país activando todos los recursos a través de las sociedades económicas, pero que siguió mirando a la pesca por detrás de la agricultura, la industria y el comercio. Sin embargo, los más importantes tratadistas contemplaron la pesca como un recurso a mejorar, desde Ustáriz a Campomanes, pasando por Gándara o Ward. Las tres sociedades canarias -Gran Canaria, Tenerife y La Palma- intentaron apoyar la pesca, pero "con medidas que iban de arriba abajo", en busca de "un alimento barato para una demanda que crecía debido a una población en expansión demográfica", mientras la Corona, que ya en la segunda mitad del siglo sintió la presión internacional, poco pudo hacer para fomentar una industria que tuvo siempre un carácter local, por más que Carlos III ordenara proteger las pesquerías donde las hubiera. En resumen, los autores resaltan el pesimismo del final de la época reformista: "la pesca en el Banco Sahariano continuó siendo un sector moribundo dentro de la economía marítima del siglo XVIII". Pero no ocurrirá así en adelante, pues aquellos esfuerzos de los ilustrados de las sociedades económicas o de los primeros proyectistas canarios serán las bases de "los futuros proyectos de explotación industrial del banco pesquero sahariano durante la segunda mitad del siglo XIX". 
Hay aún otro capítulo que contribuye a dotar a la obra de la sensación de exhaustividad: la caza de las ballenas y las primeras ideas conservacionistas, intuiciones del perjuicio del esquilmo que las nuevas técnicas podían producir. Entre ellas estaba la casi improvisada en las islas de cazar ballenas, lo que la Sociedad Económica de Las Palmas planteó en 1778. No había tradición en Canarias, pero el alejamiento de los españoles de Terranova después de Utrech y el aumento de la demanda de la grasa de estos animales en Europa motivaron las primeras expediciones de caza, pensando en la rentabilidad de los muchos productos derivados de estos grandes mamíferos que se comercializaban. Tras los primeros fracasos -explicados por el arponero en persona (que llegó a recibir los honores de la Sociedad)-, hubo algunas capturas, pero no los frutos esperados. "Fue la historia de una frustración, pues únicamente hirieron a diversas ballenas y capturaron unas pocas crías, con una inversión completamente deficitaria que quedó definitivamente abandonada a finales del Antiguo Régimen". Quizás lo más interesante del intento fue la reflexión de los que tempranamente se plantearon el conservacionismo en el mar.

El final del libro contiene unas acertadas conclusiones y una completa bibliografía, muy necesaria por ser éste un tema todavía con muchas parcelas a desbrozar. En suma, obra de maestros consumados en el tema, necesaria para ampliar la visión histórica allende los mares y huir de los reduccionismos acostumbrados, también para acercarse a la historia de África, en la que sin duda Juan Manuel y Germán Santana son hoy las referencias más importantes en España junto con el maestro Carlos Martínez Shaw.

José Luis Gómez Urdáñez Universidad de La Rioja 